\title{
Terapia larval sob a ótica do paciente
}

\section{Larval therapy from the patient's perspective}

\section{Terapia larval bajo la óptica del paciente}

\author{
Simone Maria da Silva', Rejane Medeiros Millions², Rita de Cássia Almeida³, João Evangelista da Costat,*
}

\section{ORCID IDS}

Silva SM (D) https://orcid.org/0000-0002-2290-5332

Millions RM (D) https://orcid.org/0000-0001-9541-6516

Almeida RC (D) https://orcid.org/0000-0002-1109-4888

Costa JE (D) https://orcid.org/0000-0003-2257-3611

\section{COMO CITAR}

Silva SM; Millions RM; Almeida RC; Costa JE. Terapia larval sob a ótica do paciente. ESTIMA, Braz. J. Enterostomal Ther., 2020, 18: e3020. https://doi.org/10.30886/estima.v18.963_PT

\section{RESUMO}

Objetivo: descrever a percepção do paciente submetido à terapia larval. Método: estudo qualitativo, exploratório-descritivo, tendo como técnica de coleta de dados e referencial metodológico a historia oral, na modalidade da história oral de vida. Participaram do estudo seis pacientes com feridas de difícil cicatrização, acompanhados pela comissão de curativos de um hospital escola em Natal, Rio Grande do Norte, submetidos à terapia larval. Resultados: os depoimentos dos pacientes/colaboradores apontam diversos valores, como crença, medo, aceitação, melhora da ferida e da dor. Revelaram que não há grande objeção e que o esclarecimento em relação ao tratamento instituído mostrou-se importante na decisão de aceitação. Conclusão: os sentimentos expressos pelos pacientes, como melhora da ferida, diminuição da dor e odor, otimização do processo de cicatrização, surgimento de centelhas de esperança quanto ao retorno à sua vida, dentre outros traduzem os benefícios da Terapia Larval (TL). Apesar do fervilhamento provocado pelo movimento do animal sobre a área acometida e da repulsa que causa a alguns profissionais e pessoas, a TL foi considerada maravilhosa, especialmente por sua eficácia na limpeza da ferida sem a necessidade de novos procedimentos invasivos como desbridamento cortante e cirúrgico.

DESCRITORES: Assistência centrada no paciente; Cicatrização de ferida; Terapia biológica; Estomaterapia.

\footnotetext{
1. Empresa Brasileira de Serviços Hospitalares - Ambulatório de Dermatologia - Setor de Curativo - Natal (RN), Brasil.

2. Escola Superior de Enfermagem do Porto - Porto, Portugal.

3. Universidade do Porto - Porto, Portugal.

4. Universidade Federal do Rio Grande do Norte - Hospital Universitário Onofre Lopes - Natal (RN), Brasil.

*Autor correspondente: dacostajoaoevangelista@gmail.com

Recebido: Out. 13, 2020 | Aceito: Nov. 26, 2020
} 
ABSTRACT

Objective: to describe the perception of the patient undergoing larval therapy. Method: qualitative, exploratory-descriptive study, using oral history as a data collection technique and methodological framework, in the form of oral life history. Six patients with difficultto-heal wounds participated in the study, followed by the dressing committee of a teaching hospital in Natal, Rio Grande do Norte, undergoing larval therapy. Results: the testimonies of the patients/collaborators point to various values, such as belief, fear, acceptance, improvement of the wound and pain. They revealed that there is no major objection and that clarification regarding the treatment instituted proved to be important in the acceptance decision. Conclusion: the feelings expressed by the patients, such as improvement of the wound, reduction of pain and odor, optimization of the healing process, emergence of sparks of hope regarding the return to their life, among others, translate the benefits of Larval Therapy (LT). Despite the seizure caused by the animal's movement over the affected area and the disgust it causes to some professionals and people, LT was considered wonderful, especially for its effectiveness in cleaning the wound without the need for new invasive procedures such as cutting and surgical debridement.

DESCRIPTORS: Patient-centered care; Wound healing; Biological therapy; Stomatherapy.

\section{RESUMEN}

Objetivo: describir la percepción del paciente sometido a terapia larval. Método: estudio cualitativo, exploratorio-descriptivo, teniendo como técnica la de recolección de datos y referencial metodológico la historia oral, en la modalidad de la historia oral de vida. En el estudio participaron seis pacientes con heridas de difícil cicatrización, con seguimiento de la comisión de curaciones de un hospital escuela en Natal, Rio Grande do Norte, sometidos a terapia larval. Resultados: los testimonios de los pacientes/colaboradores señalaron diversos valores, como creencias, miedos, aceptación, mejora de la herida y del dolor. Revelaron que no hay gran objeción y que la aclaración con relación al tratamiento instituido se mostró importante en la decisión de aceptación. Conclusión: los sentimientos expresados por los pacientes, como mejora de la herida, disminución del dolor y olor, optimización del proceso de cicatrización, surgimiento de chispas de esperanza en cuanto al retorno a su vida, entre otros traducen los beneficios de la Terapia Larval (TL). A pesar de la convulsión provocada por el movimiento del animal sobre el área afectada y de la repulsión que causa a algunos profesionales y personas, la TL fue considerada maravillosa, especialmente por su eficacia en la limpieza de la herida sin necesidad de nuevos procedimientos invasivos como desbridamiento cortante y quirúrgico.

DESCRIPTORES: Asistencia centrada en el paciente; Cicatrización de herida; Terapia biológica; Estomaterapia.

\section{INTRODUÇÃO}

Cuidar do paciente com ferida cutânea, em especial a ferida crônica, é desafiador, complexo, abrangente e requer habilidade, conhecimento científico, visão holística e trabalho multiprofissional ${ }^{1}$.

Para diversos pacientes, a ferida pode ter significados muito além da ordem física, muitas vezes é uma imperfeição, é algo que gera restrições, como limitação de movimento, dificuldades no desenvolvimento de atividades laborais, de lazer e locomoção, os receios e medos, isolamento social, dor e odor, interferem no cotidiano, repercutindo em desequilíbrios social e emocional ${ }^{1-3}$.

Nesse sentido, faz-se mister considerar, no planejamento terapêutico, a percepção do paciente sobre sua ferida, dificuldades de cura, possibilidades de tratamento, tempo de resolução do problema e não somente a escolha do curativo e cobertura.

O mercado dispõe de um leque de produtos de diferentes tamanhos, modelos e composição com finalidade de manutenção do microclima, remoção de debris, proteção do tecido de granulação, dentre outros ${ }^{4,5}$.
O presente estudo versa sobre uma das possibilidades terapêuticas que reune inúmeros benefícios e preprara o leito da ferida para receber uma dessas coberturas, que é a Terapia Larval (TL), também conhecida como: maggot therapy, larvoterapia, bioterapia ou biocirurgia ${ }^{6-9}$. É uma miíase terapêutica, artificial, induzida e controlada por uma equipe de profissionais que monitora todo o processo, desde a captura da mosca na natureza, até a aplicação e remoção das larvas na pessoa com ferida ${ }^{7-9}$.

São colocadas larvas vivas de espécies de moscas necrobiontófagas, previamente descontaminadas, com a intenção de promover a cicatrização $0^{6-9}$. A ação larval vai muito além do desbridamento biológico, perpassando pela modulação da resposta imune e liberação de substâncias com capacidade desinfetante ${ }^{7,10}$. É uma terapia considerada segura e amplamente utilizada em vários países ${ }^{11}$.

Os continentes que fornecem e distribuem larvas para finalidade terapêutica são: Europa (Reino Unido, Alemanha, Áustria, Eslovênia, Eslováquia, Croácia); Ásia (Japão, Irã, Israel, Coreia do Sul, Malásia, Filipinas, Singapura e Arábia Saudita); África (Egito); e Oceania (Austrália) ${ }^{12}$. 
Apesar de ser uma técnica mundialmente conhecida pela comunidade científica e apresentar resultados eficazes, no Brasil seu uso está restrito a cobaias, à exceção do trabalho desenvolvido no Hospital Universitário Onofre Lopes (HUOL), que em 2012 iniciou as primeiras aplicações da larva em humanos para o tratamento de feridas de dificil cicatrização, com pionerismo no uso da espécie Chrysomya megacephala (Calliphoridae $)^{13-15}$.

Os casos tratados demontraram resposta eficaz à TLe as vantagens identificadas foram: tecido de granulação exuberante, liberação de enzimas com propriedade antimicrobiana, rapidez no processo de digestão da necrose, seletividade, velocidade no reparo tecidual, fácil manuseio tanto no doente internado quanto em domicílio e ambulatório ${ }^{13,14}$.

\section{OBJETIVO}

Descrever a percepção do paciente com ferida de difícil cicatrização submetido à TL.

\section{MÉTODO}

Trata-se de uma pesquisa qualitativa, exploratória e descritiva, tendo como técnica de coleta de dados e referencial metodológico a historia oral, na modalidade da história oral de vida. Segundo Meihy ${ }^{16}$, essa modalidade significa um conjunto de experiências de vida de uma pessoa, narrada por ela, no qual a percepção é muito mais subjetiva do que objetiva.

Partindo do princípio que cada pessoa tem uma história, com suas particularidades e singularidades, a história oral de vida atende às questões norteadoras deste estudo e justifica, ainda, a escolha dos métodos, procedimentos e técnicas de acordo com as especificidades da investigação científica proposta.

A pesquisa foi realizada no HUOL, situado na cidade de Natal, estado do Rio Grande do Norte, Brasil. Instituição de atendimento hospitalar pertencente à Universidade Federal do Rio Grande do Norte (UFRN). A escolha pelo cenário supracitado se deve ao fato desse ser considerado, no Brasil, o primeiro e único a utilizar a TL para o tratamento de feridas em seres humanos ${ }^{13,14}$.

Assim, após a autorização da diretoria-geral para realizar a pesquisa e aprovação do Comitê de Ética em Pesquisa da Liga Norte Riograndense Contra o Câncer (CEP/LIGA), sob protocolo 108947/2016, foram selecionados através das fichas de atendimento ao paciente com ferida do HUOL os participantes chamados de "colaboradores" (todos os pacientes submetidos à TL no período de 2012 a 2016), perfazendo o total de 11 colaboradores.

Foram entrevistados seis colaboradores. Entre os 11 selecionados, 3 foram a óbito antes do início do estudo, 1 não aceitou participar e 1 teve que interromper as entrevistas por agravamento do quadro de saúde.

Ao serem convidados a participar da pesquisa, foi-lhes apresentada a proposta, receberam esclarecimentos sobre seu caráter científico, justificativa, objetivos, resultados esperados, bem como a relevância de suas contribuições.

Para coleta de dados, utilizou-se como instrumento a entrevista semiestruturada com questões abertas relacionadas à vivência do ser cuidado antes de adoecer, o convívio com a ferida de difícil cicatrização, impressões iniciais sobre a TL, os sentimentos quanto à larva em seu ferimento e as mudanças ocorridas após o tratamento com a TL.

As entrevistas aconteceram no mês de setembro de 2016, de forma privativa, em dia, hora e local escolhidos por eles, que preferiram, majoritariamente, sua própria residência como cenário, e por se sentirem mais à vontade suas lembranças fluíram espontaneamente. Cada colaborador concedeu 2 entrevistas com duração média de 2 horas.

Os depoimentos foram registrados em gravação digital de aúdio e resguardaram as premissas exigidas pela Resolução 466/2012 do Conselho Nacional de Saúde, que dispõe sobre as pesquisas que envolvem seres humanos, foi assinado o Termo de Consentimento Livre e Esclarecido (TCLE) e a carta de anuência.

Ao término das entrevistas, os relatos foram submetidos à transcrição, que é o processo de recriação das falas dos colaboradores, transformando-as em relatos literários, que posteriormente foram conferidos e aprovados por eles, em conformidade com a metodologia proposta.

Para o registro das reações, posturas e expressões dos colaboradores utilizou-se um diário de campo, nesse foi anotado o "tom vital", que corresponde a uma frase ou palavra que sintetiza a narrativa ${ }^{16}$.

A fim de garantir o anonimato dos colaboradores, em conjunto com eles, foram escolhidos nomes fictícios representados por pássaros canoros pertencentes à fauna brasileira, pela livre associação do texto de Santos que versa sobre a comunicação dos pássaros ${ }^{17}$.

$\mathrm{Na}$ abordagem interpretativa escolhida, procurou-se descrever cada experiência respeitando a forma como ela foi vivenciada, sob a perspectiva do colaborador. 


\section{RESULTADOS}

Neste espaço, será apresentada a história de vida de cada colaborador, incluindo as características sociodemográficas e particularidades de suas trajetórias de vida, que perpassa o período antes do adoecimento, o tratamento com a TL até os dias atuais. As narrativas revelaram "tons vitais" que possibilitaram a compreensão de fenômenos concretos a partir da vivência do colaborador.

\section{Caracterização dos colaboradores}

As características sociodemográficas dos colaboradores incluiram: idade entre 27 e 72 anos, 5 do sexo masculino e 1 do sexo feminino, dos quais $84 \%$ apresentam diabetes mellitus com complicações advindas dela, especialmente a amputação. Na mesma proporção está o nível de escolaridade, em que cinco possuem ensino médio completo e um ensino fundamental incompleto, desses, quatro são casados e dois solteiros, a maior parte recebe até um salário mínimo proveniente da previdência. A religião é predominantemente católica (apenas um evangélico).

\section{A vivência do ser cuidado antes de adoecer}

Ao serem indagados acerca de sua vida antes de adoecer, as respostas que emergiram remetem-se ao surgimento da doença, em especial “a diabetes" e o advento da ferida. Pouco se falou no ser sadio.

Antes da diabetes eu era um cara que vivia bem, trabalhava dia e noite e não sentia nada, até que surgiu um ferimento embaixo do meu pé, daí comecei a sofrer. (Azulão)

Na verdade minha vida era muito tranquila, até que apareceu esse simples arranhão no meu pé aqui ao lado que demorou a sarar, então um amigo perguntou de minhas taxas, fui para o médico, fiz os exames e soube que tinha diabetes. (Galo de Campina)

Antes de descobrir a diabetes eu tinha uma vida normal, fazia de tudo, depois que descobri comecei a regrar algumas coisas, tirar da minha vida, mas continuei teimando, eu brincava com a diabetes, brinquei, brinquei e ela acabou comigo, ela me venceu. (Fim Fim)

Convivo com a doença desde 77, quando tive uma trombose venosa em minha perna, aí eu fiquei internada quase 30 dias e minha perna ficou bem inchada, que eu tive de perder. (Coleirinha)
Eu tinha de 5 a 6 anos quando minha mãe me levou para um hospital e descobriu que eu tinha diabetes tipo 1. Convivi, na verdade, tô convivendo até hoje com essa doença. (Trinca Ferro)

\section{O convívio com a ferida de dificil cura}

A presença do ferimento foi representada principalmente por conflitos, medo, angústia, vergonha, desesperança e superação, em que a história da ferida converge para a própria história de vida.

Conviver com a ferida às vezes é desespero, eu olho desesperado pensando em alguma coisa, mas é muito difícil. (Fim Fim)

As dificuldades de ter uma ferida foram grandes, eram grandes, porque era o pé todinho e tinha que mobilizar ele todinho, mas vi sofrer mesmo quando acabou o tratamento, sofri muito, muito mesmo, eu pensei que não ia escapar.(Azulão)

Conviver com a ferida queira ou não é complicado, eu tenho muito medo de bater, não posso pisar, ando agora com muletas pra não colocar o pé no chão, porque eu tenho medo, e não se pode usar qualquer sapato. (Galo de Campina)

Conviver com a ferida é péssimo, eu não sei o que é tomar um banho debaixo do chuveiro, porque não posso molhar, faz mais de dois anos que não boto uma saia, não faço mais nada, deixei de fazer hidro por causa dessas minhas pernas, e até pra caminhar era difícil, isso incomodava, isso ardia era como pimenta, minha filha. Ah! E tem a vergonha, a gente sente vergonha. (Coleirinha)

Pra mim conviver com a ferida é como viver num sonho, é só cuidar dela que nada lhe acontece. (Trinca Ferro)

\section{As impressóes iniciais sobre a terapia larval}

Ao serem questionados quais foram as suas primeiras impressões acerca da $\mathrm{TL}$, as respostas apresentadas reforçam dados já descritos na literatura. Em suas falas, o desejo de melhora e cura foi preponderante na aceitação da TL ${ }^{6}$.

Como eu queria ficar bom, me perguntaram e eu aceitei, essa foi minha impressão. (Sabiá)

Quando me perguntaram se eu queria usar as larvas, eu disse: quero é ser o pioneiro, quero ser o primeiro mesmo! Pode meter bronca, se é para o meu bem eu quero.(Fim Fim)

A enfermeira falou comigo, disse que era uma experiência que já tem até nos Estados Unidos, e minha primeira impressão foi a seguinte, se é para melhorar minha vida, eu aceito, aceitei e me dei bem. (Azulão) 
A minha primeira impressão foi: ah, essa porcaria em cima de mim! Pra ser sincera, no primeiro momento eu não gostei, mas a gente faz tudo pra ficar boa, então eu fiz, botei, duas vezes e não me arrependo, colocaria novamente se fosse preciso. (Coleirinha)

\section{Os sentimentos quanto à larva em seu ferimento}

No decorrer das entrevistas, as sensações relatadas pelos colaboradores são comuns, entre elas: fervilhamento, comichão, arranhãozinho, formigueiro e às vezes nada.

Senti os bichinhos fervilhando, colocaram elas, eu vim pra casa e passei a noite bem, no outro dia já à noite, foi que eu senti fervilhando; é porque elas estavam evoluindo e estavam fazendo efeito. (Sabiá)

Eu não sentia nada porque o pé era dormente, se eu disser a você que eu sentia é mentira, eu não sentia nada. Às vezes tinha 200 e tantas bichinhas dentro do pé eu nem sabia que tinha. (Fim Fim)

Quando estava com as larvas na ferida sentia aquela fervilhadazinha, isso a partir do segundo dia, mas não incomodava em nada, eu me sentia era bem, porque não mais doia, era só aquele fervilhamento gostoso. (Azulão)

Eu sentia como aquele formigueiro, mas não sentia dor, não sentia mais nada. (Galo de Campina)

Ah, não me incomodou não, só sentia o caminhar delas, mas nada que tirou meu sono, não deixei de tomar banho, nem de dormir e comer. (Coleirinha)

Só sentia coçando quando elas andavam pra comer o tecido morto, só isso. (Trinca Ferro)

\section{As mudanças ocorridas após o tratamento com a terapia larval}

Nos depoimentos, os colaboradores enalteceram a melhora na cor do leito, dizendo ficar "vermelho". Para eles ocorreram mudanças significativas ao longo do tratamento, e fatores como limpeza e melhora da dor foram relatados, o que poderá influenciar no processo de expansão da TL entre os portadores com feridas de difícil cura e profissionais da saúde, já que resultados positivos incitam a aceitação do método.

Enquanto estava fazendo o tratamento com as larvas eu me dei bem, eu não sentia mais dor, não sentia chuchada nem nada, que antes o pé parecia que estava dentro de uma coivara de fogo, era queimando. O pé desinchou, as larvas comeram todas aquelas carnes podres, a ferida ficou bem vermelhinha. (Azulão)
Usei larvas duas vezes, quando tirou a primeira vez já vi uma diferença, estava bem enxutinho, bem vermelhinho, tudo tranquilo, mas não foram colocadas novas larvas por terem morrido, só na quarta-feira é que vieram novamente, dessa vez foram colocadas cerca de 80 larvas, quando tiraram na sexta feira meu pé estava uma bênção, recebi alta e fiquei indo para o ambulatório da comissão. Eu achei maravilhoso, um tratamento fantástico! (Galo de Campina)

Ela limpou né, as larvas limparam tudo e não foi agressivo. Quando a gente colocou as larvas que tirou depois de dois dias estava tudo vermelhinho, tirou aqueles tecidos mortos todos, comeu tudo, foi muito bom, eu não achei ruim não, se tivesse sido ruim eu dizia. (Coleirinha)

Eu acredito que quem suporte vale a pena, elas fazem a limpeza mesmo. (Sabiá)

Meu péficou bem vermelhinho a ponto de fechar.(Trinca Ferro)

\section{Síntese das narrativas (tom vital)}

Após a leitura minuciosa das histórias narradas, escolheu-se o "tom vital" correspondente à frase ou palavra que servirá de epígrafe para a leitura das entrevistas ${ }^{16}$, que poderiam ser agrupados e interpretados, intencionando compreender as histórias de vida dos colaboradores.

Tom vital Sabiá: Mas eu acredito que quem suporte vale a pena, elas fazem a limpeza mesmo.

Ao perceber que sua ferida não evoluia com os tratamentos convencionais, não hesitou ao aceitar o tratamento com a TL. No entanto, não suportou a sensação de fervilhamento que a larva provocou. Referiu, em seu relato, que acredita ser uma alternativa viável, tendo em vista que o curto espaço de ação suportado resultou em uma melhora no estado da ferida.

Tom vital Fim Fim: Se é para o meu bem, eu quero!

Para Fim Fim, a TL foi um tratamento excelente por ser indolor, rápido e eficiente, porém a falta de larvas descontinuou o programa, coincidindo com o agravamento da ferida e posterior amputação do membro inferior. Fim Fim afirmou, todavia, que certamente recomendaria o tratamento a quem necessitasse.

Tom vital Azulão: Durante o tempo que usei as larvas eu gostei, foi bom.

Azulão ressaltou que sentia muitas dores antes do tratamento e que ficou muito surpreso com a rapidez dos 
resultados. No entanto, a descontinuidade do tratamento com TL, devido à falta de larvas, ocasionou piora da ferida e agravamento, resultando na amputação de um pé. Comentou, finalizando a narrativa, que indicaria o tratamento, porque realmente é bom.

Tom vital Galo de Campina: Eu achei maravilhoso, um tratamento fantástico!

Galo de Campina apontou que o tratamento com TL foi muito importante e eficaz, em apenas duas aplicações sentiu a diferença, embora tenha se sentindo muito ma ao ver as larvas mortas ao final de uma sessão. Enfatizou a rapidez do tratamento e comentou que faria novamente, além de indicar para outras pessoas.

Tom vital Coleirinha: E tem a vergonha também, a gente fica envergonhada.

Coleirinha relatou ter realizado inúmeros tratamentos antes da TL, ao longo de anos da presença da lesão, inclusive a câmara hiperbárica, descrevendo as limitações e o isolamento social consequente. Revela que, inicialmente, sentiu nojo ao ser informada que as larvas seriam colocadas no seu corpo, mas, como queria ser curada, aceitou. Apesar de não ser diabética, não sentiu dor durante as aplicações. Não se arrependeu e garante que, atualmente, tem observado melhora progressiva, conseguindo até mesmo andar novamente.

Tom vital Trinca Ferro: Pra mim, conviver com a ferida é como num sonho, é só cuidar dela e nada lhe acontece.

Aparentemente, Trinca Ferro enfrentou com serenidade as dificuldades e limitações impostas pela diabetes tipo I e insuficiência renal crônica (com tratamento dialítico), além de um transplante renal e a trombose em um dos membros inferiores. Quanto ao tratamento com a TL, assevera que não sentia dor, apenas prurido e fervilhamento suportáveis aos movimentos da larva no leito da lesão. Salientou que foi orientado pela equipe de enfermagem sobre os cuidados autônomos e que não está andando devido à nova lesão, dessa vez no pé contralateral.

\section{DISCUSSÃO}

Ao referir-se ao tratamento com a TL, cada colaborador expressou, de forma diferenciada, suas inquietações, desconfianças, perplexidade, satisfação, entre outros. Tal fato é compreensível e esperado, tendo em vista a influência de crenças e valores que cada um carrega consigo, como parte indissolúvel de sua história de vida. Denota-se, no entanto, aspectos convergentes em suas narrativas: a melhora surpreendentemente rápida das condições gerais da ferida, o impacto provocado na qualidade de vida e a superação de limitações.

Diferentes pesquisas sobre as vantagens da TL para a cicatrização de feridas e aceitabilidade à terapêutica têm sido publicadas e outras sendo conduzidas. Há relatos de seus benefícios desde o tempo das guerras. No século XVI, durante a batalha de Sainti Quentin, Arizona (1509-1590), o cirurgião Ambroise Paré relatou os efeitos benéficos das larvas. Do mesmo modo, ao longo das guerras napoleônicas, o cirurgião Dominique Jean Larrey (1966-1842), observou melhora no processo cicatrial dos soldados feridos e que eram parasitados por larvas. Em meados de 1914-1918, o cirurgião William S. Baer diz ter visto "o mais belo tecido de granulação que se possa imaginar" ao observar as feridas de duas pessoas parasitadas por larvas ${ }^{18}$.

Um recente estudo fez uso da TL em um paciente com ferida de dificil cicatrização, a domicilio, guiado pela telesaúde e seu resultado demonstrou eficácia, efetividade no desbridamento, diminuição de custos com hospitalização e procedimento cirurgico e diminuição no processo infeccioso ${ }^{19}$. Outro estudo evidenciou ação bactericida e bacteriostática nas secreções e excreções larvais da espécie Cochliomyia macellaria sobre duas importantes bactérias, Staphylococcus aureus e Pseudomonas aeruginosa ${ }^{7}$. Corroborando Nezakati et al. ${ }^{20}$,realizaram um ensaio clinico triplo cego na cidade Shahroud,Irã,evidenciando também importante ação contra bactérias aerugina, Escherichia coli e Staphylococcus aureus, mas com pouco efeito sobre Enterococcus. Masiero et al. ${ }^{21,22}$ identificaram significativa atividade das espécies Chrysomya megacephala e Lucilia cuprina contra o biofilme. $\mathrm{Na}$ cidade de Oaxaca, México, foram aplicadas larvas em dois pacientes para tratar gangrena de Fournier, com a intenção de diminuir o número de procedimentos cirúrgicos, e os resultados foram promissores, pois com apenas uma intervenção cirúrgica e desbridamento larval posterior foi evidenciado o desaparecimento do tecido necrosado, controle da infecção e crescimento do tecido de granulação 9 .

No Centro-Oeste do Brasil realizou-se uma pesquisa por meio de um questionário que objetivou conhecer a opinião de pessoas internadas sobre a TL como opção terapêutica. Foram entrevistados 105 pacientes e o resultado desmotrou que o medo de perder a vida, bem como o conhecimento acerca do tratamento e de seus benefícios foram condições para aceitação da técnica ${ }^{6}$. A baixa divulgação é um fator dificultador para a aceitabilidade da TL no Brasil ${ }^{15}$. 
Os resultados encontrados sobre os benefícios da TL corroboram os apresentado neste estudo, visto que a maioria relatou melhora na qualidade de vida pelo alívio da dor e rapidez na evolução do processo de reparação tecidual. Os achados ampliaram os conhecimentos sobre a TL e sua aceitabilidade, revelando que não houve grande objeção por parte dos pacientes, e que o desejo de melhorar, o medo de novas intervenções cirúrgicas, da perda do membro ou de parte dele, a resposta reduzida ou ausente aos tratamentos convencionais e o esclarecimento sobre o tratamento foram preponderantes para a tomada de decisão.

Estudos ratificam que a interação entre o profissional e o paciente é um fator significativo, uma vez que a relação mantida entre ambos é fundamental para a adesão do paciente ao tratamento e consequentemente ao processo de cura ${ }^{1,3,6}$.

Vale destacar que o enfermeiro, profissional que está diretamente envolvido na assistência à pessoa com ferida, tem um papel fundamental nesse proceso. É de sua competência avaliar a pessoa lesionada e prescrever o cuidado mais adequado, além de realizar, orientar e supervisonar a equipe de enfermagem na execução do curativo ${ }^{3,4}$.

Acredita-se que a abordagem qualitativa embasada na história oral permitiu que os pacientes/colaboradores do estudo expressassem suas histórias de vida, dificuldades, percepções, medos e angústias sobre a terapia. Aos pesquisadores coube ouvir tais experiências com toda a riqueza de detalhes que os relatos trouxeram.

A limitação do estudo é caracterizada pela amostra de seis pacientes, contudo sua relevância se confirma por ser o único a versar sobre a percepção dos pacientes submetidos à terapia com larvas no Brasil.

\section{CONCLUSÃO}

Os sentimentos expressos pelos pacientes, como melhora da ferida, diminuição da dor e odor, otimização do processo de cicatrização, surgimento de centelhas de esperança quanto ao retorno a sua vida, dentre outros traduzem os benefícios da TL. Apesar do fervilhamento provocado pelo movimento do animal sobre a área acometida e da repulsa que causa a alguns profissionais e pessoas, a TL foi considerada maravilhosa, especialmente por sua eficácia na limpeza da ferida sem a necessidade de novos procedimentos invasivos como desbridamento cortante e cirúrgico.

Foi unânime que a TL levou aos colaboradores chances de manter o membro ou parte dele, com menores limitações para realizarem suas atividades diárias, bem como aumentou a crença na cura da ferida.

Um dos grandes nós críticos foi a descontinuidade do tratamento devido à falta de larvas, o que ratificou a necessidade de maior envolvimento dos gestores de todas as esferas no intuito de empreender esforços para a inserção da terapia no âmbito do sistema de saúde pública.

Enseja-se que a apreensão dessas narrativas incite discussões, pesquisas entre os profissionais de saúde, particularmente o enfermeiro, acerca dos benefícios da técnica, estimulando sua inserção como uma prática integrativa nas unidades de saúde a fim de promover maior qualidade de vida às pessoas com feridas de difícil cicatrização.

\section{CONTRIBUIÇÃO DOS AUTORES}

Conceitualização: Silva SM, Millions RM e Costa JE; Metodologia: Millions RM, Almeida RC e Silva SM; Investigação: Silva SM,; Millions RM e Almeida RC; Redação - Primeira versão: Costa JE e Silva SM; Redação - Revisão \& Edição: Silva SM, Millions RM e Costa JE; Aquisição de Financiamento: Silva SM e Millions RM; Recursos: Silva SM e Millions RM; Supervisão: Costa JE e Millions RM.

\section{REFERÊNCIAS}

1. Ferreira GE, Costa CO, Richter SA, Pichek E, Santos EP, Kaiser DE et al. Concepções multiprofissionais sobre a integralidade no cuidado à pessoa com lesão de pele. Enferm Bras. 2017 Abril/Set; [citado em 2020 set 07]; 16(5):259-66. Disponível em: https://www.researchgate.net/publication/328175949
2. Gomes E, Donoso MTV, Alvarenga AW, Gouveia VR. Compreendendo os significados de se conviver com ferida crônica. Rev Enferm Atenção Saúde [Online] 2018 Ago/ Set;7(2):176-88. https://doi.org/10.18554/reas.v7i2.2396 
3. Araújo WA, Assis WC, Vilela ABA, Boery RNSO, Rodrigues VP, Rocha RM. Signifi-cados de viver com ferida crônica: estudo de metassíntese. ESTIMA, Braz J Enterostomal Ther 2020;18:e2420. https://doi.org/10.30886/estima.v18.936_PT

4. Silva RM, Fernandes FAV. Competências do Gestor de Feridas: scoping review. Rev Gaúcha Enferm 2019;40:e20180421. https://doi.org/10.1590/1983-1447.2019.20180421

5. Silva ACO, Filho ESR, Sousa GRS, Silva JFS, Silva AL, Araújo CMS. As principais coberturas utilizadas pelo enfermeiro. Revista Uningá. 2017 Jul/Set; [citado em 2020 ago 08]; 53(2):117-23. Disponível em: http://revista.uninga.br/index. php/uninga/article/view/1426

6. Franco LC, Franco WC, Barros SBL, Araújo CM, Rezende HHA. Aceitabilidade da te-rapia larval no tratamento de feridas. Revista Recien 2016 Maio/Jul; [citado em 2020 set 06]; 6(17):13-8. Disponível em: https://www.recien.com.br/ index.php/Recien/article/download/144/217

7. Masiero FS, Aquino MFK, Nassu MP, Pereira DIB, Leite DS, Thyssen PJ. First record of larval secretions of Cochliomyia macellaria(Fabricius, 1775)(Diptera: Calliphoridae)in-hibiting the growth of Staphylococcus aureus and Pseudomonas aeruginosa. Neotrop En-tomol 2017;46(1):125-9. https://doi. org/10.1007/s13744-016-0444-4

8. Marcondes CB. Terapia larval de lesões de pele causadas por diabetes e outras doenças. Florianópolis: editora UFSC; 2006. p.88.

9. Fonseca-Muñoz A, Sarmiento-Juménez HE, Pérez-Pacheco R, Thyssen PJ, Sherman R. Clinical study of Maggot therapy for Fournier's gangrene. Int Wound J 2020;1-8. https://doi. org/10.1111/iwj.13444

10. Power G, Moore Z, O `Connor T. Measurent of pH, exudate composition and temperature in wound healing: a systematic review. J Wound Care 2017;26(7):381-97. https:// doi.org/10.12968/jowc.2017.26.7.381

11. International Biotherapy Society. Maggot Debridement Therapy (MDT). [citado em 2020 set 06]. Disponível em: http://biotherapysociety.org/maggot-debridement-therapymdt/

12. Stadler F. The maggot therapy supply chain: a review of the literature and practice. Med Vet Entomol 2020;34(1):1-9. https://doi.org/10.1111/mve.12397

13. Pinheiro MARQ, Ferraz JB, Junior MAA, Moura AD, Costa MESM, Costa FJMD et al. Use of maggot therapy for treating a diabetic foot ulcer colonized by multidrug resistant bacteria in Brazil. Indian J Med Res 2015;141(3):340-2. https://doi. org/10.4103/0971-5916.156628
14. Ferraz JB, Pinheiro M, Gama RA. Biocirurgia. In: Blank M, Giannini T, organizadores. Úlceras e Feridas: as feridas tem alma. Rio de Janeiro: Di Livros; 2014. p.864.

15. Brambilla PBT. Terapia larval e Divulgação Científica no Brasil: Até quando serão ne-gligenciadas? [trabalho de conclusão de curso]. Natal (RN): Universidade Federal do Rio Grande do Norte; 2018. Disponível em: https:// monografias.ufrn.br/jspui/bitstream/123456789/7947/5/ TerapiaLarvalDivulgacaoCientifica_Brambilla_2018.pdf

16. Meihy JCSB. Manual de História oral. 5.ed. São Paulo: Loyola; 2005. v 1. $291 \mathrm{p}$. HOLANDA F. História oral: como fazer, como pensar. 3 edição. São Pau-lo- SP: Contexto, 2015.P 169

17. Santos ASR. A importância da vocalização na identificação das aves. Boletim CEO n.10. São Paulo; p.27-33. 1994. [citado em 2020 set 07]. Disponível em: http://www.ceo.org. br/bolet/bolceo10.pdf

18. Sherman RA. Mechanisms of maggot-induced wound healing: what do we know, and where do we go from here? Evid Based Complement Alternat Med 2014;2014:1-13. https://doi.org/10.1155/2014/592419

19. Armstrong DG, Rowe $V L$, D'Huyvetter $K$, Sherman RA. Telehealth-guided home-based maggot debridement therapy for chronic complex wounds: Peri- and postpandemic potential. Int Wound J 2020;17(5):1490-1495. https://doi.org/10.1111/iwj.13425

20. Nezakati E, Hasani MH, Zolfaghari P, Rashidan M, Sohrabi MB. Effects of Lucilia sericata Maggot Therapy in Chronic Wound Treatment: A Randomized Clinical Tri-al. Chronic Wound Care Management and Research 2020;7:11-7. https://doi.org/10.2147/CWCMR.S248149

21. Masiero FS, Silva DG, Luchese M, Estércio T, Pérsio NV, Thyssen PJ. In vitro eval-uation of the association of medicinal larvae (Insecta, Diptera, Calliphoridae) and topical agents conventionally used for the treatment of wounds. Acta Trop 2019;190:68-72. https://doi.org/10.1016/j. actatropica.2018.10.015

22. Masiero FS, Aguiar ESV, Pereira DIB, Thyssen PJ. First ReportontheUse ofLarvae ofCochliomyiamacellaria(Diptera: Calliphoridae)forWoundTreatmentinVeterinaryPractice.JMed Entomol2020;57(3):965-8.https://doi.org/10.1093/jme/tjz238 